\title{
A UTILIZAÇÃO DO SOFTWARE GEOGEBRA NO ENSINO DA TRIGONOMETRIA NA EDUCAÇÃO BÁSICA
}

\author{
Fábio Mendes Ramos ${ }^{1}$ \\ Cristiane Aparecida Lisboa ${ }^{2}$ \\ Daniel Martins Nunes ${ }^{3}$
}

\begin{abstract}
RESUMO: A técnica de ensino escolhida como objeto de pesquisa para o desenvolvimento deste trabalho é a aplicada nos laboratórios e oficinas escolares, nos quais há a utilização de ferramentas e recursos tecnológicos para ensino da disciplina de matemática. Tal técnica permite ao professor conduzir as aulas de maneira dinâmica instigando a curiosidade e prendendo a atenção dos alunos, aprofundando assim os conceitos que estão sendo trabalhados teoricamente em sala de aula. Visto que tais técnicas de ensino possuem um papel fundamental na educação é necessário compreender o lugar que as mesmas devem ocupar no processo pedagógico. Nesse sentido apresenta-se aqui uma pesquisa sobre a utilização do Software GeoGebra no Ensino de Funções Trigonométricas na Educação Básica a fim de elaborar propostas que possam colaborar com o uso desse recurso em sala de aula apresentando condições favoráveis ao ensino aprendizagem. Para tanto faz-se nesta uma breve discussão sobre o uso de tecnologias no Ensino da Matemática e desafios nesse encontrados, como: a formação de professores e suas atuações na profissão, Ensino de Funções Trigonométricas e uso do Software GeoGebra. A pesquisa foi classificada como qualitativa embasada na opinião de pesquisadores sobre a utilização das inovações tecnológicas na Educação Básica.
\end{abstract}

Palavras-chave: Ensino de Matemática. Formação de Professores. Funções Trigonométricas. GeoGebra.

\footnotetext{
I Doutorado em andamento no Programa de Pós-Graduação em Ensino de Ciências Exatas pela UNIVATES. Mestre em Ensino de Ciências e Matemática pela PUC Minas e graduação em Matemática pela UNIMONTES. Professor de Matemática do Instituto Federal de Educação, Ciências e Tecnologia do Norte de Minas Gerais - IFNMG, com experiência na docência do Ensino Básico, Técnico e Superior. Pesquisador na área de Educação Matemática, Objetos de Aprendizagem e Tecnologia no Ensino. Email: fabio.ramos@ifnmg.edu.br.

2 Graduada em Matemática pelo Instituto Federal do Norte de Minas Gerais - IFNMG. Email: lisboacristiane@yahoo.com.br.

3 Doutorado em andamento no Programa de Pós-Graduação em Educação pela UFSCar. Mestre em Matemática pela UESB e graduação em Licenciatura em Matemática pela Unimontes. Professor de Matemática do Instituto Federal de Educação, Ciência e Tecnologia do Norte de Minas Gerais - IFNMG, com experiência na docência do Ensino Básico, Técnico e Superior. Pesquisador na área de Educação Matemática e Tecnologia no Ensino. E-mail: daniel.nunes@ifnmg.edu.br.
} 
ABSTRACT: The teaching technique chosen as the object of research for the development of this work is applied in laboratories and school workshops, in which tools and technological resources are used to teach the subject of mathematics. This technique allows the teacher to conduct classes dynamically, instigating curiosity and holding students' attention, thus deepening the concepts that are theoretically being worked on in the classroom. Since such teaching techniques have a fundamental role in education, it is necessary to understand the place they should occupy in the pedagogical process. In this sense, we present here a research on the use of GeoGebra Software in the Teaching of Trigonometric Functions in Basic Education in order to develop proposals that can collaborate with the use of this resource in the classroom, presenting favorable conditions for teaching and learning. Therefore, a brief discussion on the use of technologies in Mathematics Teaching and challenges encountered in this is made in this, such as: teacher training and their performance in the profession, Trigonometric Functions Teaching and the use of GeoGebra Software. The research was classified as qualitative based on the opinion of researchers on the use of technological innovations in Basic Education.

Keywords: Mathematics Teaching. Teacher training. Trigonometric Functions. GeoGebra.

\section{INTRODUÇÃO}

As discussões e as pesquisas sobre a formação de professores têm ganhado um grande espaço nos tempos atuais, visto que se vive em um período de inovações constantes, por isso faz-se necessário compreender o processo dessa formação e criar meios de aperfeiçoá-la para

obtenção de melhores resultados na educação dos envolvidos, em especial do alunado. Sendo importante ressaltar que o foco principal de tal formação é o professor, uma vez que, de acordo com Fiorentini (2003, p. 9):

quase todos falam do professor como profissional reflexivo, investigador de sua prática, produtor de saberes, elemento-chave das inovações curriculares na escola e principal responsável pelo seu desenvolvimento profissional. FIORENTINI (2003, p. 9)

Porém, o que percebemos é que ainda prevalece a prática de ensino tradicional sem muitas brechas para prática de um ensino inovador, já que os professores enfrentam grandes dificuldades em transmitir os conteúdos, utilizando mecanismos e estratégias diversificadas, diferentes do modelo em que a maioria deles se formou, que foram por meio de aulas majoritariamente teóricas. Assim, hoje, diante do avanço tecnológico educacional, possibilitando inúmeras inserções de ferramentas no ambiente escolar, visando a facilitação do aprendizado dos alunos, percebe-se a disponibilidade de acesso à informatização em muitas instituições de ensino, porém pouco, ou quase nada, delas explorada pelos professores por estes não terem domínio o suficiente para explorarem o conhecimento dos alunos ou até 
mesmo por estarem acostumados aos métodos tradicionais de ensino que se resumem apenas a aplicação das teorias e resolução de exercícios.

Percebe-se que entre os educadores em sala, os professores de Matemática tornam-se os mais criticados, sendo acusados frequentemente de não adotarem continuamente uma formação diferenciada a fim de acabar com a formação tradicional por meio da atualização dos cursos de licenciatura (FIORENTINI, 2003). Vale ressaltar, contudo, que existem sinais que indicam que são esses professores em especial que geralmente se arriscam por caminhos diferentes para as novas expectativas. Sendo assim, é preciso considerar que as mudanças são contínuas na vida profissional de qualquer professor, tanto na sua carreira quanto no seu modo de desenvolvimento, o que pode resultar tanto em avanço ou retrocesso (FIORENTINI, 2003).

No processo inicial de formação de professores existe uma verdadeira sociedade de envolvidos, e por essa razão essa experiência é vivenciada como problemática, visto que cada ser envolvido se encontra em um estágio de evolução pessoal (BLANCO, 2003). Desse modo, ainda segundo Blanco (2003, p. 5I-52):

$$
\begin{aligned}
& \text { um aspecto do problema, relativo à "formação de professores” seria a definição de } \\
& \text { programas de formação que respondessem às demandas provenientes dos distintos } \\
& \text { setores afetados; um programa que possibilitasse a formação de profissionais do } \\
& \text { ensino com capacidade para desenvolver suas tarefas no âmbito de sua própria e } \\
& \text { contínua aprendizagem e desenvolvimento profissional. BLANCO (2003, p. 51-52) }
\end{aligned}
$$

Esse problema possui responsabilidades divididas entre diferentes grupos envolvidos no processo. Especificamente no que se refere a pesquisas da educação matemática, faz-se necessário haver a obtenção de estruturas teóricas e embasamento conceitual, propiciando a construção de um programa de formação inicial de professores do ensino de tal disciplina que atenda às diversas e distintas demandas, além de possibilitar a composição dos fundamentos para essa formação. Diante dessa necessidade, surgiram questionamentos que dizem respeito ao professor e ao processo de sua formação que levantaram diferentes abordagens e expectativas.

Outro desafio enfrentado pelos professores no ensino da Matemática nas escolas é a escolha dos livros didáticos, já que o Ministério da Educação (MEC) determina quais livros serão disponibilizados, porém sendo poucas as opções de escolha, ou seja, tais livros já vêm pré-escolhidos por um sistema que não leva em conta a convivência com o aluno, com a comunidade, nem com a cultura de cada região. Consequentemente, os professores ficam 
insatisfeitos, por não possuírem o direito de opinar na escolha do livro didático que será utilizado por eles durante a explanação dos conteúdos.

Nesse sentido, como a maioria dos livros apresentam atividades e textos fora do contexto em que vivem os alunos, o aprendizado é dificultado consideravelmente. Em contrapartida torna-se muito mais eficaz trabalhar a teoria atrelada a uma prática vivenciada no cotidiano da turma do que por uma realidade distante dela. Somando se outro problema constante que é a não disponibilização da quantidade suficiente de exemplares dos livros escolhidos para atender a demanda de alunos atendidos ou, até o fato de que, depois de uma longa reunião para essa escolha, simplesmente os modelos selecionados não chegarem até a escola. Ainda sobre o recurso didático que contemple o contexto social dos alunos, Sopelsa, Gazzóla e Detoni (2014, p. 9) afirmam que:

[...] Seja o livro didático, seja qualquer outro material didático pedagógico utilizado na escola, ele precisa contemplar a articulação com o contexto social dos alunos, o ensino e a aprendizagem matemática não se realiza de forma objetiva, mas sim contextualizada de forma subjetiva. SOPELSA, GAZZÓLA E DETONI (2014, P. 9)

A par disso tudo, tem-se que a realidade de aprendizagem dos alunos é muito diferente do que o sistema educacional propõe-se a realizar. Os livros, assim como todos os materiais didáticos, que chegam até o ambiente escolar para o uso e manuseio do professor, foram construídos tendo como base a vida e realidade de alunos que não possuem nenhuma dificuldade de aprendizagem, que são membros de "famílias estabilizadas" e que participam de suas vidas escolares dando lhes todo o apoio para se sobressaírem nos estudos, entretanto, essa infelizmente não é a realidade da maioria dos alunos das escolas públicas do país.

Especificamente no estudo de Matemática prevalecem algumas etapas em tal processo de ensino aprendizagem que precisam ser levadas em conta, quais sejam: aceitação, hesitação, iluminação, entre outros. E os professores desempenham um importante papel no desenvolvimento delas, fazendo com que o tempo gasto pelos alunos na escola então deva ser o mais bem aproveitado possível. Existe então a necessidade de os professores trabalharem primeiramente com as dificuldades dos alunos, ministrando o conteúdo de forma clara e precisa, visando sempre ao entendimento desse pela classe, aprimorando e aliando os conhecimentos teórico e prático, utilizando diversos recursos para facilitação da aprendizagem. Nesse sentido, saber utilizar devidamente os recursos tecnológicos durante 
as aulas é uma alternativa que leva a se conseguir um melhor resultado no desempenho dos educandos.

\section{TÉCNICA DE ENSINO}

A técnica de ensino escolhida para o desenvolvimento do presente trabalho é a utilizada nos laboratórios e oficinas escolares com recursos e ferramentas tecnológicas disponíveis. Consistindo em complementar as aulas teóricas trabalhadas comumente em sala de aula com a prática e utilização das tecnologias e conseguir com essa associação uma maior obtenção de aprendizagem do conteúdo pelos alunos.

Espera-se, com essa associação, que os alunos despertem maior interesse pela construção do seu conhecimento, uma vez que tal técnica permite ao professor conduzir as aulas de maneira dinâmica, instigando a curiosidade e mantendo a atenção dos alunos por mais tempo ao assunto, aprofundando assim conceitos ora trabalhados teoricamente em sala de aula. Sendo ainda importante ressaltar que a diversidade na forma de dar aula, avaliar os alunos e desenvolver as demais atividades educacionais contribuem de forma significativa na obtenção dos resultados esperados pelo professor diante dos objetivos propostos para suas aulas, que é a absorção do conteúdo pelo alunado.

Nesse sentido, a aprendizagem acontece mais facilmente quando os alunos envolvidos percebem o objetivo do conteúdo ministrado pelo professor, isto é, entendem em que utilizarão de verdade os conceitos e práticas trabalhadas (MORAN, 2008).

Moran (2008, p. 24), ainda nesse contexto, afirma que “[...] aprendemos mais, quando conseguimos juntar todos os fatores: temos interesse, motivação clara; desenvolvemos hábitos que facilitam o processo de aprendizagem; e sentimos prazer no que estudamos e na forma de fazê-lo". Assim, por meio da criatividade e aplicabilidade do professor na utilização das técnicas de ensino esse aprendizado pode ser alcançado com muito mais facilidade, já que aulas dinâmicas e menos cansativas são benéficas a todos envolvidos.

É importante ressaltar que as técnicas de ensino compõem o processo pedagógico escolar (ARAÚJO, 2007), sendo assim, elas correspondem a um dos elementos utilizados na composição do processo pedagógico e, por conseguinte, possuem o mesmo nível de importância que os demais elementos. Desse modo, tais técnicas, de acordo com Araújo (2007, p. 13), “[...] estabelecem relações com a totalidade social, dispõem, portanto, de uma 
autonomia relativa e subordinada a outros aspectos componentes do referido processo". Existindo assim portanto uma relação de dependência entre as técnicas de ensino e os demais componentes do processo pedagógico escolar.

Para Veiga (2007, p. 13i), nesse contexto, “[...] é função do professor organizar o processo de ensino, o que ele fará, evidentemente, recorrendo à escolha deliberada e intencional de determinadas formas, em detrimento de outras", pois o professor tem a responsabilidade de escolher de que forma conduzirá o processo de ensino em sala de aula, tendo êxito, desde que, é claro, respeite as vinculações sociopolíticas da educação.

Em relação ao processo de ensino utilizado nos laboratórios e oficinas escolares, Veiga (2007, p. 131) também destaca que:

[...] uma vez que não existem técnicas igualmente aplicáveis ao ensino de todas as disciplinas, faz-se necessário que as técnicas voltadas para a aula nos laboratórios e oficinas escolares sejam alvo de uma análise mais aprofundada, por serem escassos os estudos sobre elas. VEIGA (2007, p. 131)

Visto que são inexistentes técnicas aplicadas de forma igualitária ao ensino das disciplinas, torna-se importante ainda ressaltar aqui a necessária análise profunda sobre essas técnicas, sendo importante um maior aprofundamento nesse estudo para um melhor encaixe das mesmas a cada realidade (VEIGA, 2007).

\section{ENSINO DA TRIGONOMETRIA}

A abordagem da trigonometria na Educação Básica inicia-se no último ano dos anos finais do Ensino Fundamental e estende-se até o Ensino Médio. Sobre o primeiro momento, no Ensino Fundamental, Silva (2013, p.17) explica que:

[...] são introduzidos os conceitos de seno, cosseno e tangente no triângulo retângulo, e no ensino médio, quando se trabalham os conceitos de arcos, ângulos e suas unidades de medidas (graus e radianos); o ciclo trigonométrico; identificação das razões trigonométricas neste círculo; equações; as funções trigonométricas e seus gráficos e a resolução de problemas que envolvem trigonometria. (SILVA, 2013, p. 17).

Os Parâmetros Curriculares Nacionais (PCNs) têm como objetivo fornecer orientações a todas as instituições de ensino da Educação Básica quanto aos conhecimentos fundamentais e competências que os alunos têm o direito de adquirir e, também, aqueles que são esperados que adquiram durante a vida escolar dentro dessa modalidade de ensino. Isso sendo independente das condições socioeconômicas em que tais educandos vivam em suas comunidades. Entretanto, a comunidade escolar sabe que os PCNs não ditam 
obrigatoriamente o que os professores devem fazer em suas salas de aula, trata-se apenas de referências para direcioná-los sem engessamento (SILVA, 2013). Nessa perspectiva:

outro tema que exemplifica a relação da aprendizagem de matemática como desenvolvimento de habilidades e competências é a trigonometria, desde que seu estudo esteja ligado às aplicações, evitando-se o investimento excessivo no cálculo algébrico das identidades e equações para enfatizar os aspectos importantes das funções trigonométricas e da análise de seus gráficos. Especificamente para o indivíduo que não prosseguirá seus estudos nas carreiras ditas exatas, o que se deve ser assegurado são as aplicações da trigonometria na resolução de problemas que envolvam medições, em especial o cálculo de distâncias inacessíveis, e na construção de modelos que correspondam a modelos periódicos (SILVA, 2013, p. 17).

Portanto, durante o aprendizado matemático do conteúdo de trigonometria, devem ser trabalhados e explorados os principais conceitos e análises gráficas que proporcionem ao aluno condições para a resolução de problemas dentro do seu nível de ensino, pois só haverá necessidade de aprofundamento e detalhamento de tal conteúdo para os interessados em ingressar em cursos específicos da área de exatas e possível construção de carreira profissional naquelas.

Levando-se em conta o anteriormente exposto, e, apesar de não se tratar de assunto novo no âmbito educacional, o presente estudo, vem a colaborar e apresentar propostas de elaboração de atividades no ensino de funções trigonométricas, isso a partir de atividades manipuláveis no Software GeoGebra, de forma prática, dinâmica e acessível aos alunos.

Figura r: Função seno

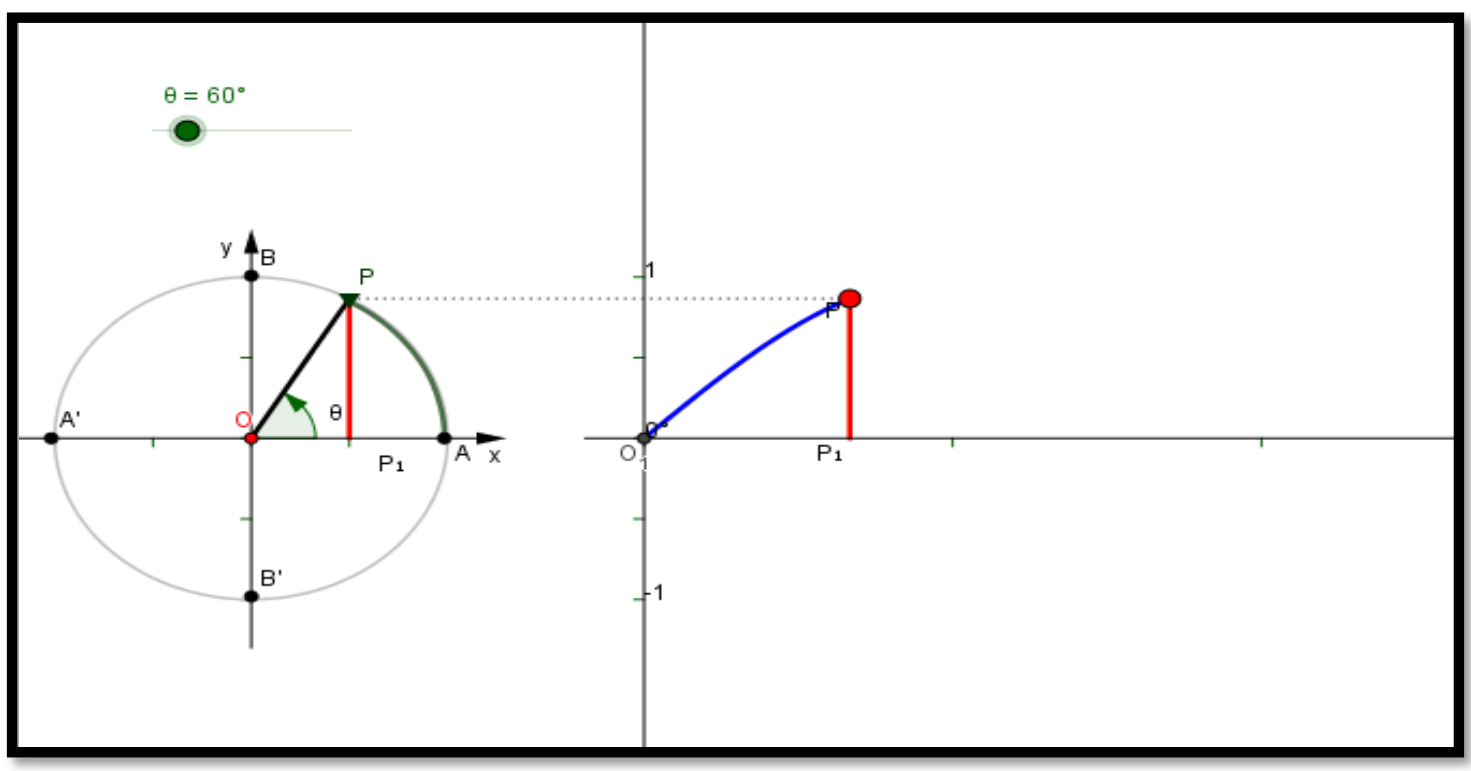

Fonte: Elaborada pela autora, 2019 
Essas atividades citadas explorariam o conteúdo de funções trigonométricas, partindo das manipulações dos objetos, de forma conceitual, algébrica e geométrica. E a partir dessa manipulação os próprios alunos poderiam observar o comportamento gráfico das funções e aprofundar os conceitos adquiridos em sala de aula de maneira mais prática e palpável.

\section{O USO DO GEOGEBRA COMO FERRAMENTA PEDAGÓGICA}

O GeoGebra é um software permite a construção de objetos gráficos e sua manipulação. Então, na construção de gráficos, o usuário de tal ferramenta pode observar o comportamento dos objetos criados pela movimentação permitida na janela gráfica, que por sua vez se localiza à direita da tela exposta, assim como acompanhar algebricamente, na janela à esquerda, os acontecimentos (BORGES, 2009).

Figura 2- Gráfico das funções, trigonométrica e modular de seno e cosseno.

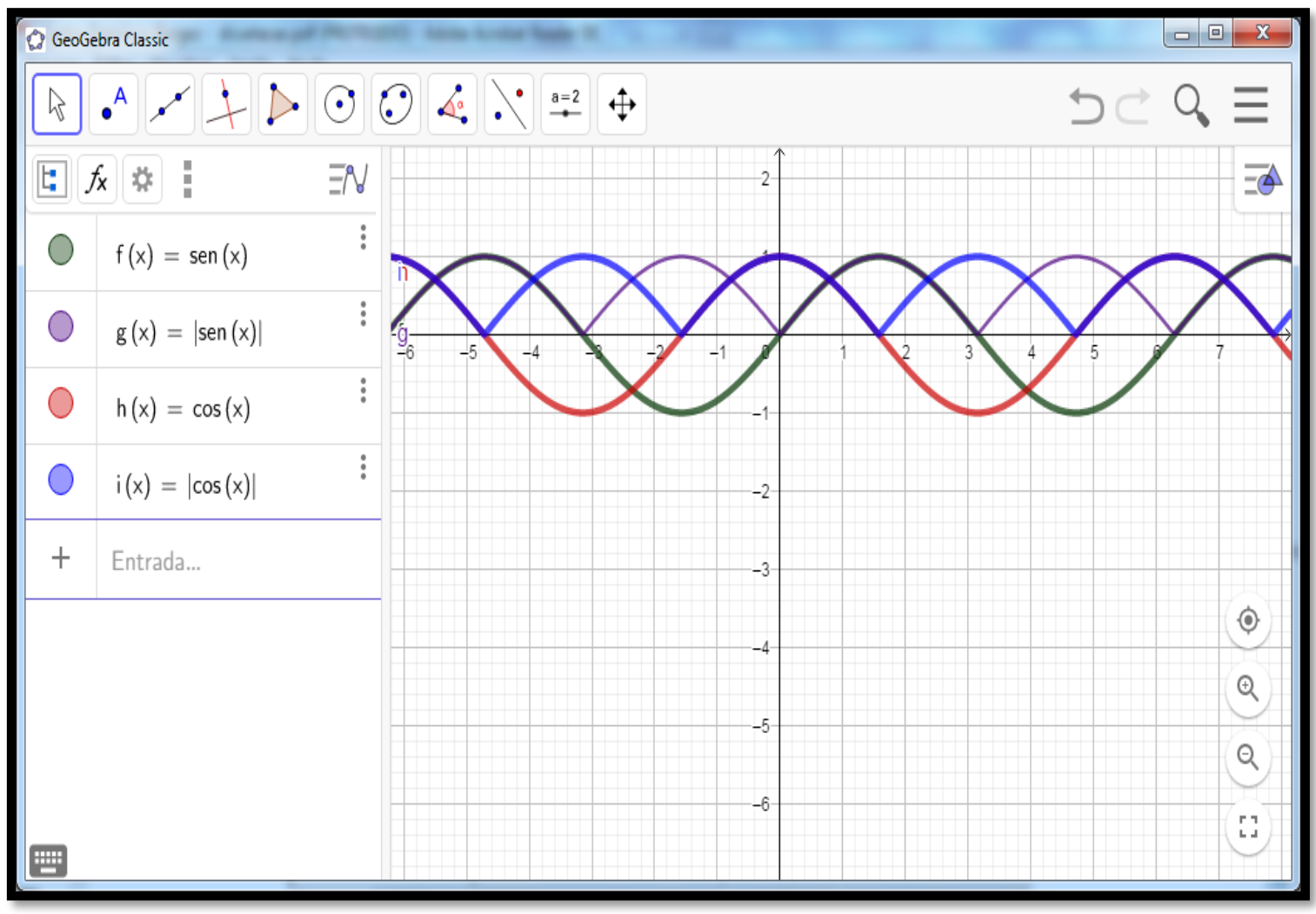

Fonte: Elaborada pela autora, 2019 
Entre as diversas ferramentas que auxiliam os educandos no seu processo de aprendizagem, o computador é um que aparece como um grande aliado e importante representante das ferramentas da informática. Por meio dele, são utilizados grande parte dos softwares educativos que auxiliam no ensino das mais variadas disciplinas em sala de aula laboratórios e demais ambientes.

O uso de softwares educacionais possui a função especial de permitir aos educandos maior interação com o conteúdo ministrado pelo professor, sendo portanto que a introdução de técnicas de ensino que incluam recursos tecnológicos, como o software GeoGebra, apresenta uma grande possibilidade de obtenção de resultados positivos para a aprendizagem dos alunos (SAVI; ULBRICHT, 2008).

Embora se viva num mundo tecnologicamente avançado, a maioria dos ambientes educacionais ainda se utilizam apenas dos métodos tradicionais de ensino, com aulas conduzidas apenas pelo livro didático, giz e quadro, seguidos em boa parte da aplicação de exercícios para fixação do conteúdo trabalhado. Apesar de essas modalidades em aulas ainda serem necessárias e importantes, isso não significa que devem ser as únicas metodologias utilizadas para exposição e explanação de conteúdos.

Nesse contexto, o computador, assim como o uso da internet, pode contribuir, de forma significativa e positiva, com o aprendizado dos alunos. Isso desde que o professor possua conhecimento adequado para utilização desses recursos, conduzindo a execução das atividades de forma mais prática e funcional. O que, pelo contrário infelizmente ainda ocorre, em algumas instituições de ensino, é o fato de professores conduzirem seus alunos para sala ou laboratório de informática, deixando-os livres para manusearem os computadores, sem um planejamento de aula, tornando as ferramentas improdutivas e sem nexo com o assunto estudado em sala. Se usados dessa forma, os recursos tecnológicos, ao invés de benefícios, tendem a destruir a educação dos alunos e os prejudicar em seu desenvolvimento.

Contudo, vale ressaltar que o avanço tecnológico promoveu uma grande contribuição na educação em todos os campos do saber, e não seria diferente no ensino da trigonometria, uma vez que, por meio do surgimento de várias tecnologias e da informatização do ensino, surgiram excelentes softwares geométricos, como o aqui citado Geogebra, que permite uma 
grande exploração dos conceitos trigonométricos de maneira mais dinâmica. Sobre esse software em especial, Borges (2009, p. 38) afirma:

o Geogebra possui todas as ferramentas tradicionais de um software de geometria dinâmica: pontos, retas, segmentos, circunferências, arcos, secções cônicas, além de uma janela de álgebra que mostra as equações e as coordenadas de um ponto. Por isso apresentam a vantagem didática de mostrar ao mesmo tempo a conversão entre duas representações diferentes de um mesmo objeto, as representações gráficas e algébricas. BORGES (2009, p. 38)

Dessa forma, o GeoGebra auxilia a explanação da matéria pelo professor, tornandoa mais prática e interessante, pois, quando é feita a representação gráfica e algébrica ao mesmo tempo, os alunos percebem e assimilam o conteúdo de maneira mais eficaz e em um menor tempo, o que leva ao real aprendizado do assunto e às suas variadas possibilidades de utilização prática no cotidiano.

\section{CONSIDERAÇÕES FINAIS}

Este trabalho apresentou um pequeno estudo sobre os conceitos, teorias e exemplificações para educadores que tenham interesse em conhecer ou aprofundar seus conhecimentos na área do ensino de matérias da Matemática e que visem à obtenção de resultados positivos, isso de maneira especial por meio da técnica de ensino a ser utilizada em laboratórios e oficinas presentes nas escolas, auxiliando-os, assim, no planejamento, desenvolvimento e na realização de aulas mais significativas e práticas.

Diante da revisão bibliográfica proposta, e que baseou o presente trabalho, o resultado esperado é que esta pesquisa incentive a criatividade dos educadores na utilização do software GeoGebra durante o ensino de trigonometria na Educação Básica despertando, portanto, interesse nos leitores em aplicar ou utilizar o conteúdo aqui proposto como embasamento de trabalhos que possam ser desenvolvidos com os alunos.

O trabalho apresentou as propostas que partem do uso do recurso tecnológico denominado softwareGeoGebra, a ser usado durante o processo de ensino-aprendizagem de Funções trigonométricas, nas aulas de Matemática, o qual contribuiria com os métodos e técnicas de ensino já utilizados, aperfeiçoando-os, já que, como exposto aqui, são importantes na construção do conhecimento do aluno sobre os mais variados assuntos. 


\section{REFERÊNCIAS}

ARAÚJO, José Carlos de Souza. Para uma análise das representações sobre as técnicas de ensino. In: VEIGA, Ilma Passos Alencastro (org.). Técnicas de ensino: por que não? I8 Ed. Campinas: Papirus, 2007.

BORGES, Carlos Francisco. Transição das razões trigonométricas do triângulo retângulo para o círculo trigonomético: uma sequência para ensino. São Paulo: Editora, 2009.

FIORENTINI, Dario. BLANCO, Maria Mercedes García. Formação de professores de matemática: explorando novos caminhos com outros olhares. A Formação inicial de professores de matemática: fundamentos para a definição de um curriculum. Campinas: Editora Mercado de Letras, 2003, p. 51-86.

GAZZÓLA, Lucivani; DETONI, Marilena Zanoello. Os desafios do ensino e da aprendizagem na matemática no contexto histórico-cultural e a constituição dos saberes docentes. In: ANPED SUL, ı, Florianópolis, Anais... Florianópolis: UDESC, 2014. Disponível em: $\langle$ http://xanpedsul.faed.udesc.br/arq_pdf/515-I.pdf $\rangle$. Acesso em: o5 de set. de 2018.

MORAN, José Manuel; MASETTO, Marcos T; BEHRENS, Marilda Aparecida. Novas tecnologias e medição pedagógica. Campinas: Papirus, 2008.

SAVI, Rafael; ULBRICHT, Vania Ribas. Jogos digitais educacionais: benefícios e desafios. Renote, v. 6, n. 2, p. I-Io, 2008. Disponível em: 〈https://seer.ufrgs.br/renote/article/view/I4405/8310〉. Acesso em: 05 de set. de 2018.

SILVA, Luiz José. Trigonometria racional: uma nova abordagem para o ensino de trigonometria. Salvador/BA, 2013.

VEIGA, Ilma Passos Alencastro. Técnicas de ensino: por que não? São Paulo/SP: Papirus, 2007 (Coleção Magistério). 